\title{
THE STUDY OF HEAVY METAL POLLUTION IN SOILS AND THE LINK BETWEEN POLLUTION AND ONCOLOGICAL DISEASES
}

(C) 2018

Ashurbekova Tamila Nasirovna, candidate of biological sciences, associate professor of Ecology and Plant Protection Department

Dagestan State Agricultural University named after M.M. Dzhambulatov (Makhachkala, Russian Federation)

Musinova Elmira Mugudinovna, candidate of biological sciences, associate professor of Medical Biology Department

Dagestan State Medical University (Makhachkala, Russian Federation)

Abstract. The paper deals with the problem of ecotoxicants content: arsenic, mercury, lead, cadmium in the soils of Achkhoy-Martan District settlements of the Chechen Republic and their impact on human health. The presence of heavy metals in soils and plant samples of the studied area can be explained by the geological structure of the territory of the Republic, which is located on the rocks of the Jurassic and Paleogene periods. Studies have shown excessive concentrations of lead in some samples of soil settlements of the Achkhoi-Martan District: Samashki is 43,1 $\mathrm{mg} / \mathrm{kg}$ and Janda $-42,1 \mathrm{mg} / \mathrm{kg}$ vs $30 \mathrm{mg} / \mathrm{kg}$ by the MPC. There is an excess of the maximum permissible concentration of cadmium in the village Zakan-Yurt $-1,93 \mathrm{mg} / \mathrm{kg}$ against $1,0 \mathrm{mg} / \mathrm{kg}$ MPC. As for mobile forms arsenic, mercury and cadmium are found in the greatest quantities. The arsenic content exceeds the permissible values by $2,03-$ 3,36 times, the cadmium content exceeds the MPC by almost 2 times $-1,93 \mathrm{mg} / \mathrm{kg}$ against $1 \mathrm{mg} / \mathrm{kg}$. According to the results of the studies, the relationship between the transformation of mobile forms of heavy metals from soil to plants is monitored. A direct correlation between cancer and the concentration of heavy metals in the soils of the study areas was revealed.

Keywords: environment; soil samples; plant samples; gross forms; mobile forms; ecotoxicants; carcinogens; heavy metals; arsenic; mercury; lead; cadmium; maximum permissible concentration; Achkhoy-Martan District; Samashki; Zakan-Yurt; Yandy; Shaami-Yurt; cancer incidence; mean annual indicators; correlation coefficient.

УДК $581.9(470.315)$

DOI 10.24411/2309-4370-2018-14102

Статья поступила в редакцию 10.07.2018

\section{ХАРАКТЕРИСТИКА ПАМЯТНИКА ПРИРОДЫ ИВАНОВСКОЙ ОБЛАСТИ «ОЗЕРО ВАЗАЛЬ (ВОДОХРАНИЛИЩЕ В Г. ЮЖА)»}

(C) 2018

Борисова Елена Анатольевна, доктор биологических наук, заведующий кафедрой общей биологии и физиологии

Марков Дмитрий Сергеевич, кандидат географических наук, заведующий кафедрой экологии и географии Курганов Антон Александрович, кандидат биологических наук, доцент кафедры общей биологии и физиологии

Ивановский государственный университет (г. Иваново, Российская Федеращия)

Аннотация. В данной статье рассматриваются результаты экологического обследования памятника природы Ивановской области - «Озеро Вазаль (водохранилище в г. Южа)», проведенного в 2017 г. Водохранилище расположено в г. Южа Ивановской области, оно было образовано в 1859 г. в результате перекрытия дамбой небольшой р. Вазовка и заполнения вырытого котлована. Это водохранилище получило название озеро Вазаль. В 1975 г. данный водоем был признан памятником природы регионального значения. Описываются основные параметры озера, дана батиметрическая схема дна. Охарактеризован рельеф берегов озера. По берегам распространены дерново-неглубокоподзолистые среднемощные, дерновые средне- и слабогумусированные песчаные почвы на ледниковых отложениях. Сделан анализ воды данного водоема. Приводится описание луговых, болотных, водных и прибрежно-водных растительных сообществ ООПТ. В составе флоры к 2018 г. отмечено 277 видов сосудистых растений из 3 отделов, 4 классов, 64 семейств и 180 родов, среди них 3 вида (Sanguisorba officinalis, Lembotropis nigricans, Geranium palustre) включены в основной список региональной Красной книги, 6 редких видов - в дополнительный список растений, нуждающихся в мониторинге и охране. Кратко описаны состояние популяций редких видов, приводятся примеры адвентивных и инвазионных видов растений. Озеро имеет большое гидрологическое и средообразующее значение, формирует особый микроклимат. Площадь ООПТ составляет 42 га, площадь охранной зоны - 67,3 га.

Ключевые слова: особо охраняемые природные территории (ООПТ); озера; водохранилища; батиметрическая схема; структура почв; состав воды; растительность; флора; редкие виды растений; адвентивные виды растений; инвазионные виды растений; г. Южа; Ивановская область.

\section{Введение}

Экологическая доктрина России рассматривает развитие системы особо охраняемых природных тер- риторий как одно из ключевых направлений государственной политики в области экологии. Необходимость комплексного изучения природных экоси- 
стем рассматривается как одна из основных и приоритетных задач создания и функционирования особо охраняемых территорий [1].

В Ивановской области с 2013 г. в рамках долгосрочной целевой программы «Развитие водохозяйственного комплекса Ивановской области 20112020 гг.» ежегодно проводятся исследования водноболотных комплексов. Изучены многие озера в Южском [2-4], Савинском [5], Верхнеландеховском [6], Ильинском [7], Комсомольском [8] районах.

Озеро Вазаль находится в центральной части г. Южа и представляет собой искусственный водоем, специально вырытый для обеспечения текстильной фабрики водой. В 1859 г. при строительстве фабрики небольшую р. Вязовку (Пионерку) перегородили плотиной, и вода заполнила котлован. Жители стали называть водохранилище озером Вазаль, и это название за ним закрепилось. Над акваторией озера были построены 2 моста. Этот водоем является одной из главных достопримечательностей города, важнейшим градостроительным элементом. Он продолжает оставаться местом отдыха для жителей города и приезжающих гостей из других регионов. Озеро Вазаль признано памятником природы регионального значения в 1975 г. (РОИ от 27.01.1975 г. № 2/6). Однако специальные изучения этого озера не предпринимались, паспорт данного памятника природы отсутствовал, границы и режимы охраны не были описаны. Поэтому целью данной работы явилось проведение комплексного экологического исследования данной ООПТ.

\section{Материал и методы исследований}

Исследования озера Вазаль и прилегающих к нему территорий проводились в июне - августе 2017 г. в рамках государственного контракта с Департаментом природных ресурсов и экологии Ивановской области с целью создания паспорта данной ООПТ. Были изучены особенности рельефа берегов, проведены измерения глубин в различных частях водоема. Глубины измерялись с помощью GPS-навигатора и эхолота. Для определения морфометрических параметров и составления цифровой модели рельефа дна озера Д.С. Марковым применялись ГИС технологии - ArcGIS 10 (ESRI) и Golden Software. Для изучения почв были заложены и описаны 3 почвенных профиля.

Исследования флоры ООПТ проводились традиционно, маршрутно-рекогносцировочным методом. Маршруты были составлены, чтобы охватить все типы растительных сообществ. Был составлен полный аннотированный конспект флоры, в нем для видов указывались фенологические фазы, распространение по ООПТ, общее жизненное состояние, а также повреждения патогенными грибами и насекомымивредителями. Были описаны популяции некоторых редких видов растений. Собранные гербарные материалы хранятся в гербарии Ивановского государственного университета (IVGU), дублеты интересных видов будут переданы в Гербарий им. Д.П. Сырейщикова (MW).

Также были учтены и проанализированы имеющиеся сведения по флоре и растительности ООПТ [9; 10].

\section{Результаты исследований} и их обсуждение

По форме водохранилище Вазаль вытянутое, с лопастными отчленениями. Это крупный городской
Борисова Е.А., Марков Д.С., Курганов А.А. Характеристика памятника природы Ивановской области..

водоем. Его максимальная длина составляет 1,4 км, ширина - 0,5 км, площадь акватории - 39,0 га. Длина береговой полосы превышает 6,5 км. В целом водоем не глубокий. По измерениям его глубины, сделанным в августе 2017 г., средняя глубина составляет 1,16 м, максимальная глубина отмечена в западной части и достигает 3,5 м. Уровень воды в водохранилище колеблется в пределах 1 м: максимальная абсолютная высота уровня воды - 97,5 м, минимальная 96,5 м. Водоем открытый, его акватория хорошо освещается со всех сторон. В летний сезон мелководья хорошо прогреваются, что приводит к развитию колоний водорослей. На рисунке 1 представлена батиметрическая схема дна озера Вазаль, которая была составлена Д.С. Марковым.

Берега озера Вазаль низкие, отлогие, местами заболоченные. Рельеф берегов озера (на примере северо-восточного берега) представлен следующим образом: от уреза воды начинается озерная терраса шириной 3 м, затем идет склон коренного берега длиной 5 м с уклоном до $15^{\circ}$ высотой около 1,5 м; плакорные участки имеют уклоны 3-4․ Высота плотины водохранилища около 5 м. В районе нижнего бьефа широко развиты эрозионные процессы и оползни.

Согласно почвенному районированию Центрального нечерноземного района, территория в окрестностях ООПТ относится к зоне дерново-подзолистых почв, южно-таежной подзоне, Среднерусской провинции дерново-подзолистых среднегумусированных почв, к Горьковскому древнеаллювиальному низменно-равнинному округу, к Южскому району болотноторфяных и дерново-слабоподзолистых почв [11]. По берегам озера распространены торфяно-глеевые почвы и песчаные дерново-неглубокоподзолистые среднедерновые слабогумусированные почвы.

Были взяты пробы воды озера Вазаль и проведен их анализ на базе сертифицированной лаборатории Роспотребнадзора - ФГУЗ «Центр гигиены и эпидемиологии в Ивановской области». Результаты анализа воды представлены в таблице 1 .

По данным исследования установлено, что вода в озере характеризуется как чистая. Отмечены незначительные превышения по отдельным показателям.

Растительность. Фитоценозы ООПТ представлены сообществами луговой, прибрежно-водной и водной, сорно-рудеральной растительности. Черноольшаники крупнотравные встречаются фрагментарно, в основном в верховье водохранилища. Сомкнутость крон в данном черноольшанике - 60\%, подлесок хорошо развит, густой, в его составе отмечены Padus avium, Frangula alnus, реже встречаются Rubus idaeus, Lonicera xylosteum, Sambucus racemosa. Tpaвянистый ярус формируют крупные заросли крапивы двудомной, таволги вязолистной, дербенника иволистного, незабудки. Прибрежные кустарниковые заросли представлены сообществами с доминированием ив (пепельной, козьей, пятитычинковой, ушастой и чернеющей), реже отмечены калина обыкновенная, смородина черная, бузина раскидистая. В них обычно распространены группы манника большого, крапивы двудомной, сныти обыкновенной, веха ядовитого, дудника лесного и др. По берегам водохранилища встречаются одиночные старовозрастные деревья ивы ломкой, реже рябины обыкновенной, черемухи птичьей. 


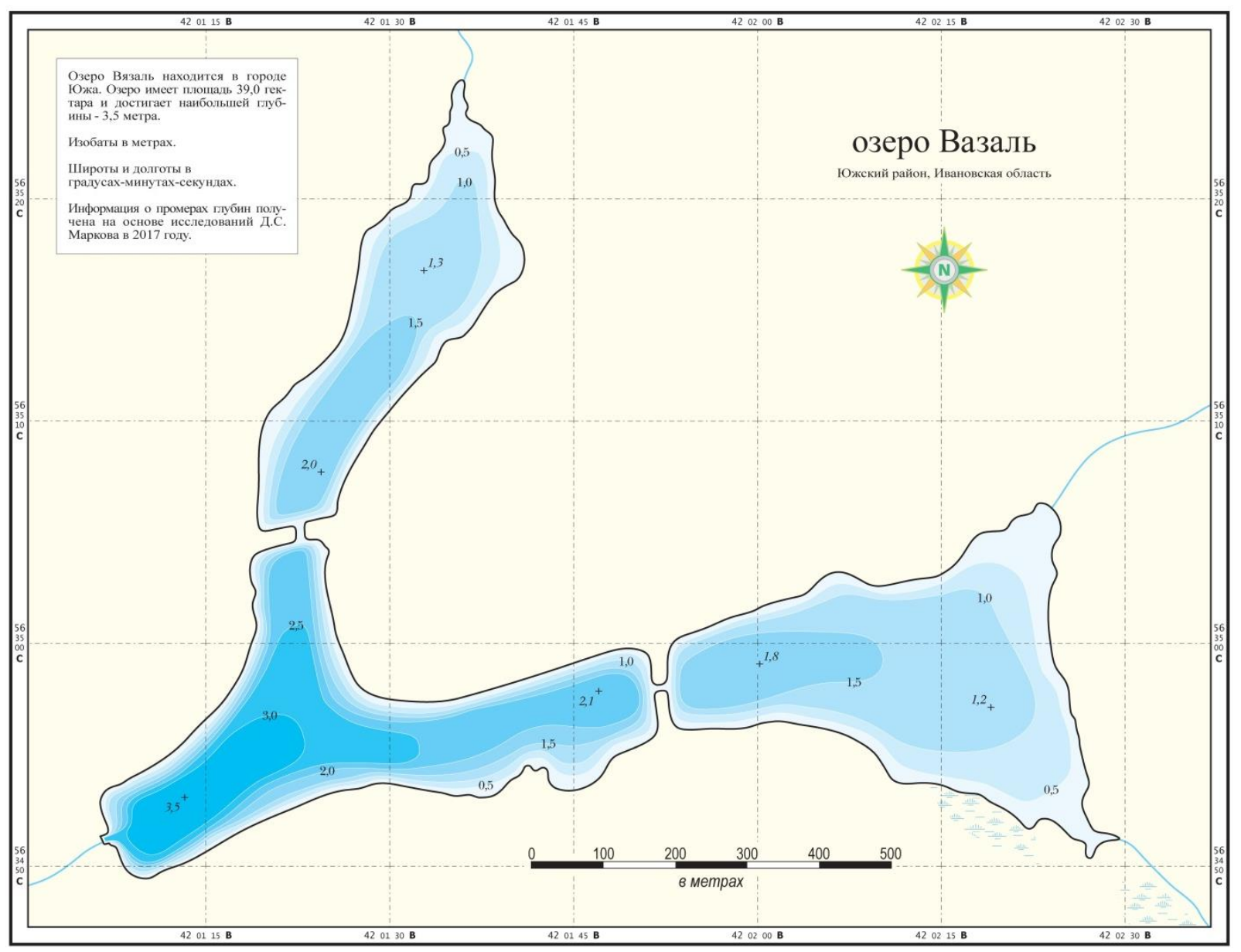

Рисунок 1 - Батиметрическая схема озера Вазаль

Та6лица 1 - Результаты анализа воды озера Вазаль

\begin{tabular}{|c|c|c|c|c|}
\hline № & Показатели & Значение & Единицы измерения & Гигиенические нормативы \\
\hline 1 & Запах при $20^{\circ} \mathrm{C}$ & 2 & балл & 2 \\
\hline 2 & Запах при $60^{\circ} \mathrm{C}$ & 3 & балл & 2 \\
\hline 3 & $\mathrm{pH}$ & 7,6 & & $6,5-8,5$ \\
\hline 4 & Мутность & 0,2 & мг/дм ${ }^{3}$ & 20 \\
\hline 5 & Цветность & 43,3 & град & 35 \\
\hline 6 & Сухой остаток & 100 & мг/дм ${ }^{3}$ & 1000 \\
\hline 7 & Жесткость общая & 2,5 & $\Psi^{\circ}$ & 7,0 \\
\hline 8 & Окисляемость перманганата & 5,1 & мг/дм ${ }^{3}$ & 7,0 \\
\hline 9 & Нефтепродукты суммарно & менее 0,1 & мг/дм ${ }^{3}$ & 0,3 \\
\hline 10 & ПАВ & менее 0,01 & мг/дм ${ }^{3}$ & 0,5 \\
\hline 11 & Фенольный индекс & отc. & мг/дм ${ }^{3}$ & 0,25 \\
\hline 12 & Растворенный кислород & 5,7 & мг/дм ${ }^{3}$ & не менее 4,0 \\
\hline 13 & БПК-5 & 2,3 & мГ/дм ${ }^{3}$ & 4,0 \\
\hline 14 & Аммиак (по азоту) & 0,7 & мг/дм ${ }^{3}$ & 1,5 \\
\hline 15 & Железо & 0,3 & мг/дм ${ }^{3}$ & 1,0 \\
\hline 16 & Медь & 0,008 & мг/дм ${ }^{3}$ & 1,0 \\
\hline 17 & Марганец & 0,086 & мг/дм ${ }^{3}$ & 0,1 \\
\hline 18 & Нитраты $\left(\right.$ по $\left.\mathrm{NO}_{3}\right)$ & 9 & мг/дм ${ }^{3}$ & 45,0 \\
\hline 19 & Нитриты $\left(\mathrm{NO}_{2}\right)$ & 0,18 & мг/дм ${ }^{3}$ & 3,3 \\
\hline 20 & Свинец & 0,008 & мГ/дм ${ }^{3}$ & 0,01 \\
\hline 21 & Сульфаты & 16,4 & мг/дм ${ }^{3}$ & 500 \\
\hline 22 & Хлориды & 15 & мг/дм ${ }^{3}$ & 350 \\
\hline 23 & Фториды & 0,1 & мГ/дм ${ }^{3}$ & 1,5 \\
\hline 24 & Цинк & 0,03 & мг/дм ${ }^{3}$ & 1,0 \\
\hline 25 & Коли-фаги & не обнаружено & КОЕ/мЛ & 10 \\
\hline 26 & Патогенные микроорганизмы & не обнаружено & МЛ & отсутствие \\
\hline
\end{tabular}


Травянистые сообщества имеют вид лентовидных ценозов (шириной от 1 до 3 м). Распространены щавелево-рогозовые сообщества с участием череды олиственной, осоки ложносытевидной, шлемника копьелистного, зюзника европейского, сабельника болотного, веха ядовитого и др. Встречаются канареечно-тростниковые сообщества с участием рогоза широколистного, щавеля прибрежного, подмаренника болотного. Обычны таволгово-осоковые (Carex acuta, C. vesicaria, C. pseudocyperus) сообщества с участием вербейника обыкновенного, вахты трехлистной, наумбургии кистецветковой, кипрея болотного и др. В верховьях водохранилища часто встречаются крупные заросли манника большого. По берегам водохранилища обычны группировки частухи подорожниковой, щавеля приречного, вейника седеющего, реже тростника южного, канареечника тростниковидного, болотницы болотниковой, камыша лесного, незабудки болотной, осоки острой, лютика ползучего и редкого вида - ириса ложноаирового. На западном берегу водохранилища отмечены крупные заросли папоротника - телиптериса болотного.

Надводная растительность в верховьях водохранилища на 70-80\% покрывает водное зеркало, плавающая - до $10 \%$, погруженная - около $20 \%$. В центральной части водоема водная растительность развивается только вдоль прибрежной полосы. Сообщества плавающих гидрофитов представлены в основном популяциями ряски маленькой и многокоренника обыкновенного, реже встречаются группы кубышки желтой, водокраса обыкновенного. Среди погруженных водных растений здесь обычны роголистник темно-зеленый, элодея канадская, реже ряска трехдольная, рдест пронзеннолистный.

Болотистые луга представлены небольшими сообществами в прибрежной зоне водоема и в понижениях. В их составе отмечены Phragmites australis, Phalaroides arundinacea, Scirpus sylvaticus, Calamagrostis canescens, Deschampsia cespitosa, Filipendula ulmaria, Juncus effusus, Juncus filiformis, Epilobium hirsutum, Galium palustre, Bidens cernua, Bidens frondosa, Cirsium arvense и др.

В составе злаково-разнотравных лугов среди злаков доминируют мятлик луговой, душистый колосок и ежа сборная, среди разнотравья встречаются обычные виды (клевер средний, чина луговая, василек луговой, вероника дубравная, зверобой пятнистый, нивяник обыкновенный, подорожник ланцетный, одуванчик лекарственный и др.). Реже встречаются высокотравные рогозово-тростниковые луга с доминированием рогоза широколистного и тростника южного. Также распространены группы осоки пузырчатой, таволги вязолистной, лютика ползучего, сивца лугового и др. По южному берегу описаны луга с доминированием вейника наземного, нередко этот вид формирует практически монодоминантые сообщества, по краям которых обычны группы тонколучника северного, мыльнянки лекарственной, колокольчика раскидистого, реже икотника серо-зеленого, зверобоя пятнистого, купыря лесного, тысячелист-
Характеристика памятника природы Ивановской области..

ника обыкновенного и др. На пологом склоне берега водохранилища были описаны редкие в Ивановской области сообщества с участием триостренника болотного (Triglochin palustre).

В зонах отдыха и на сбитых лугах распространены участки сорно-рудеральной растительности. Часто встречаются группировки бодяка полевого, мыльнянки лекарственной, лопуха паутинистного, цикория обыкновенного, овсяницы тростниковидной. Реже встречаются гвоздика турецкая, пикульник двураздельный, купырь лесной, звездчатка средняя, пустырник пятилопастный, сныть обыкновенная и др. На склонах берегов отмечены группы цветущих растений лилейника оранжевого (Hemerocallis fulva). Вдоль дорог обычны горец птичий, горец вьюнковый, дивала однолетняя, звездчатка средняя, фиалка полевая, люцерна посевная, щавели туполистный и малый, крапива двудомная, подорожник большой, кипрей горный, мать-и-мачеха обыкновенная, чертополох курчавый, желтушник левкойный и др.

Флора. К 2018 г. во флоре памятника природы и в его охранной зоне было выявлено 277 видов сосудистых растений, которые относятся к 3 отделам, 4 классам, 64 семействам. Большинство видов (269 видов) относятся к отделу покрытосеменные (Angiospermae). Отдел папоротниковидные представлен 5 видами, отдел хвощевидные - 3 видами. К числу ведущих семейств флоры ООПТ относятся сложноцветные, представленные 36 видами, злаки - 27 видами, розоцветные - 20 видами, гвоздичные - 13 видами и зонтичные - 12 видами. Из 180 родов крупными являются следующие: Carex -8 видов, Rumex6 видов, Juncus, Populus и Salix - по 5 видов каждый. Среди редких растений в охранной зоне ООПТ найдены популяции трех видов (Sanguisorba officinalis L., Lembotropis nigricans (L.) Griseb., Geranium palustre L.), которые включены в Красную книгу Ивановской области [12]. 6 видов (Matteuccia struthiopteris, Calamagrostis neglecta, Iris pseudacorus, Campanula trachelium, $C$. persicifolia, Jasione montana) относятся к редким растениям, которые занесены в «Дополнительный список сосудистых растений, нуждающихся в постоянном контроле» (приложение к Красной книге Ивановской области) [12].

Небольшая популяция (площадь 1,5 × 1 м) кровохлебки лекарственной (Sanguisorba officinalis), представленная несколькими цветущими и плодоносящими экземплярами, найдена недалеко от берега восточной части озера в районе молокозавода, в зарослях Ribes nigrum, вместе с Calamagrostis epigeios, Equisetum arvense, Phleum pratense, Urtica dioica. В регионе вид распространен в долине р. Клязьмы.

Всего один небольшой ветвистый цветущий экземпляр острокильницы чернеющей (Lembotropis nigricans) найден на сухой луговине у пилорамы, вместе с Equisetum arvense, Jasione montana, Campanula rotundifolia, Lactuca serriola, Erigeron canadensis, Taraxacum officinale. Вид приурочен к сухим соснякам на дюнных песках.

Группы цветущих особей герани болотной (Geranium palustre) найдены в придорожной луговине и на 
сыром высокотравном лугу у берега озера в охранной зоне, среди Dactylis glomerata, Phragmites australis, Melilotus albus, Valeriana officinalis. Ранее этот вид был известен в 6 районах [13].

Из других редких и интересных аборигенных видов по берегам водохранилища и на прилегающих сырых луговинах найдены и другие редкие и интересные аборигенные растения, например, гибрид двух видов пальчатокоренника (Dactylorhiza incarnata $\times$ D. fuchsii), Hierochloe odorata, Galium trifidum, Myosotis cespitosa, Polemonium caeruleum, Rubus caesius, Triglochin palustre.

Адвентивные виды во флоре ООПТ многочисленны, это связано с антропогенной нарушенностью берегов водохранилища. Водоем продолжает оставаться рекреационным объектом, на его берегах отдыхают жители г. Южи, ранее здесь работала лодочная станция, был организован городской пляж. Отдыхающие нередко оставляют мусор на берегах, жгут костры. Нередко жители прилегающих к озеру улиц сбрасывают в воду бытовые отходы, организуют небольшие свалки мусора. Всего во флоре ООПТ отмечено 56 адвентивных видов. Часть из них - беглецы из культуры (Lychnis chalcedinica, Aquilegia vulgaris, Saponaria officinalis, Malus domestica и др.). Многие относятся к обычным сорно-рудеральным видам (Arctium tomentosum, Atriplex patula, Cichorium intybus, Lactuca serriola, Setaria pumila, Sisymbrium loeselii, Tripleurospermum inodorum и др.). Среди заносных особую группу составляют инвазионные виды, внедряющиеся в природные сообщества. Среди них по берегам озера Вазаль распространены Acer negundo, Amelanchier spicata, Bidens frondosa, Echinocystis lobata, Epilobium adenocaulon, E. pseudorubescens, Populus alba. Крупные популяции формирует Impatiens glandulifera, в воде озера большие группы образует Elodea canadensis. На лугах, пустырях, вдоль дорог часто встречаются, Echinocystis lobata, Erigeron canadensis, Helianthus tuberosus, Heracleum sosnowskyi, Lepidotheca suaveolens, Phalacroloma septentrionale, Solidago gigantea. Эти растения являются инвазионными видами Ивановской области [14] и Верхневолжского региона [15], а также Средней России в целом [16].

Из редких адвентивных видов отметим Aconitum × cammarum L., который редко культивируется в регионе, как дичающий в природных сообществах был отмечен на лугу по берегу ручья у с. Илья-Высоково [17]. Также на суходольном лугу по берегу озера Вазаль обнаружена группа цветущих растений Heliopsis helianthoides Dun., который известен пока в 2-х пунктах Ивановского района $[14 ; 18]$. Группы Veronica filiformis J.E. Smith обнаружены на сорном месте по берегу озера. Этот вид в последнее десятилетие увеличивает темпы вегетативного размножения, активно внедряется в луговые ценозы различных регионов России [19]. На западном берегу вовохранилища в зарослях кустарников отмечены группы Inula helenium $\mathrm{L}$.

Водохранилище Вазаль - крупный водный объект г. Южи. Этот водоем является украшением города, формирует его микроклимат, имеет большое гидрологическое и средообразующее значение. Флора и фауна памятника природы «Озеро Вазаль» отличаются разнообразием, несмотря на расположение в городской черте, по его берегам сохранились местообитания многих редких видов растений и животных. Здесь отмечены различные виды хозяйственно ценных растений (красивоцветущих, медоносных и лекарственных), обитает 8 видов рыб. Сохраняется научно-просветительское, эстетическое и рекреационное значение этого водоема. Данная ООПТ важна для сохранения биоразнообразия региона. В планируемой экологической сети Ивановской области она входит в состав буферной зоны [20].

\section{Заключение}

На основе проведенных исследований рекомендуется сохранить озеру Вазаль статус памятника природы Ивановской области. Его площадь составляет 42 га, площадь рекомендуемой охранной зоны, необходимой для предотвращения неблагоприятных антропогенных воздействий, составляет 67,3 га.

Утверждение паспорта ООПТ с определенными границами и контроль соблюдения установленных режимов охраны позволят сохранить водохранилище в г. Южа (озеро Вазаль) как живописный водный объект. Также существенно снизится угроза загрязнения воды, заиливания дна в озере, сохранится определенный уровень биоразнообразия, стабильность экосистем, местообитания редких видов. Несомненно, повысится красота ландшафтов, привлекательность ООПТ для развития экологического туризма и рекреации. На берегах озера рекомендуется проводить различные мероприятия по экологическому образованию и воспитанию населения, разработать проект экологической тропы.

\section{Список литературы:}

1. Бубличенко А.Г. Роль научных исследований в формировании концепции охраняемых природных территорий, история и современные проблемы приморских ООПТ Санкт Петербурга и Ленинградской области // Региональная экология. 2014. № 1-2 (35). C. $145-153$.

2. Борисова Е.А., Шилов М.П., Курганов А.А. Флора и растительность озера Поныхарь // Научные труды Национального парка «Хвалынский»: мат-лы II всерос. науч.-практ. конф. Вып. 7. Саратов-Хвалынск: Амирит, 2015. С. 76-80.

3. Борисова Е.А., Шилов М.П., Марков Д.С., Курганов А.А. Памятник природы Ивановской области «Озеро Заборье» // Известия Самарского научного центра Российской академии наук. 2016. Т. 18, № 21. С. $47-50$.

4. Борисова Е.А., Курганов А.А., Марков Д.С., Шилов М.П. Озеро Нельша Ивановской области // Известия Самарского научного центра Российской академии наук. 2017. Т. 19, № 2-2. С. 229-233.

5. Борисова Е.А., Шилов М.П., Щербаков А.В., Курганов А.А. Флора озер Савинского района Ивановской области // Бюллетень Брянского отделения 
Русского ботанического общества. 2013. № 2 (2). C. 20-27.

6. Борисова Е.А., Шилов М.П., Курганов А.А. Флора и растительность ООПТ Ивановской области «Озеро Шадрино» // Самарская Лука: проблемы региональной и глобальной экологии. 2017. Т. 26, № 3. C. 87-93.

7. Борисова Е.А., Курганов А.А., Мишагина Д.А. Флора и растительность памятника природы «Озеро и болото Ценское» // Природное наследие России: сб. науч. статей междунар. научной конф., посв. 100летию национального заповедного дела и Году экологии в России (г. Пенза, 23-25 мая 2017 г.) / под ред. Л.А. Новиковой. Пенза: Изд-во ПГУ, 2017. C. $117-119$.

8. Борисова Е.А., Курганов А.А., Марков Д.С., Шилов М.П. Озеро Юрцино (Юрцинское) Ивановской области // Проблемы природопользования и экологическая ситуация в Европейской России и на сопредельных территориях: мат-лы VII междунар. науч. конф. памяти проф. Петина А.Н. (24-26 октября 2017 г.). Белгород: ПРОЛИТЕРА, 2017. С. 395397.

9. Борисова Е.А., Сенюшкина И.В. Современное состояние флоры г. Южи Ивановской области // Проблемы биоэкологии и пути их решения: мат-лы междунар. науч. конф. (Саранск, 15-18 мая 2008 г.). Саранск: Мордов. гос. ун-т, 2008. С. 29-31.

10. Борисова Е.А. Итоги изучения флоры и растительности Ивановской области // Вестник Ивановского государственного университета. Серия: Естественные, общественные науки. 2014. № 2. С. 5-10.

11. География почв и почвенное районирование центрального экономического района СССР / под ред. Г.В. Добровольского и И.С. Урусевской. М.: Изд-во Моск. ун-та, 1972. 488 с.

\section{IVANOVO REGION NATURAL MONUMENT «LAKE VAZAL (RESERVOIR IN YUZHA)» CHARACTERISTICS}

(C) 2018

Borisova Elena Anatolyevna, doctor of biological sciences, head of General Biology and Physiology Department

Markov Dmitriy Sergeevich, candidate of geographical sciences, head of Ecology and Geography Department Kurganov Anton Aleksandrovich, candidate of biological sciences, associate professor of General Biology and Physiology Department Ivanovo State University (Ivanovo, Russian Federation)

Abstract. The paper deals with the ecological research of Ivanovo Region natural monument «Lake Vazal (reservoir in town Yuzha)». The reservoir is located in Yuzha of the Ivanovo Region, it was founded in 1859 by the overlapping a small river Vazovka with dam filling a formed basin with water. This reservoir was named «Lake Vazal». The reservoir was recognized as a natural monument of regional value in 1975. The author describes different parameters of the lake and presents a bathymetric schema of the bottom. The relief of the lake banks is characterized. There are sod-shallow podzolic medium-power, medium sod medium- and low-humic sandy soils on the water-ice scurf on the banks of the lake. The water analysis is made. Meadow, marshy, aquatic and hygrophytic plant communities of this protected area are described briefly. The author has registered 277 vascular plant species from 3 divisions, 4 classes, 64 families and 180 genera, among them 3 species (Sanguisorba officinalis, Lembotropis nigricans and Geranium palustre) are included to the Ivanovo Region Red Data Book. 6 species are rare for the region flora. Populations of rare plant species are briefly characterized. Examples of alien and invasion plant species are given. The lake has a great hydrological and environment-forming value and forms a specific microclimate. The square of specially protected natural area is 42 hectares; the square of secured zone is 67,3 hectares.

Keywords: specially protected natural areas (SPNA); lakes; reservoirs; bathymetric schema; soil structure; aquatic composition; vegetation; flora; rare plant species; alien plant species; invasion plant species; Yuzha; Ivanovo Region. 